also in the left posterior triangle. The cervical "abscess" was drained. Histological appearances of tissue from the abscess wall were typical of histiocytosis $\mathrm{X}$. After radiation the area healed but over the next three years there was intermittent mucopurulent discharge from the cutaneous sinus that had formed over the right occiput and right posterior cervical region. The problem was partially controlled by increasing the dose of prednisolone, and on two occasions there was a satisfactory response to etoposide. No organism was ever isolated.

\section{Discussion}

Lymphadenopathy is well recognised in histiocytosis $\mathrm{X}^{2}$ but formation of sinuses secondary to lymph node disease is hitherto unrecorded, even among 260 patients in three major studies..$^{3+}$ Chronically discharging sinuses were the presenting feature in case 1 and occurred after many years of disease in case 2 . These lesions should not be confused with ulcerating skin plaques, which are more superficial and unrelated to nodes. Bony erosions may also break through and form dermal sinuses, but in neither of our patients did bone lesions appear to underlie the affected skin.

Histiocytosis $\mathrm{X}$ should now be recognised in the differential diagnosis of "suppurative" lymphadenopathy so that appropriate treatment may be given. The diagnosis in case 1 was delayed for over a year because of the false impression of an infective process.
Similarly in case 2 with a patient receiving corticosteroids added infection with tuberculosis or actinomycosis was thought to be responsible. In neither case, however, was any micro-organism市 isolated, and in both patients healing occurred with immunosup- $\frac{}{c}$ pressive drugs.

Though spontaneous resolution of multisystem histiocytosis $\mathrm{X}$ is occasionally seen, 'the response to steroids in this age group, as in young children, may be gratifying. Vincristine and etoposide are the most useful "second line" agents.

We thank Dr J G S Ledingham and Mr A Freeland for allowing us to report on their patient.

\section{References}

Nezelof C, Frileux-Herbert F, Cronier Sachat J. Disseminated histiocytosis X. Cancer 1979;44, U, 1824-38.

2 Sajiad SM, Osborne B. Lymph node involvement by histiocytosis X. Arch Pathol Lab Med 1982:106:96-8

3 Greenherger J, et al. Results of treatment of 127 patients with systemic histiocytosis. Medicine(Baltimore) 1981;60:311-37.

4 Avery $M$, et al. Course and prognosis of reticuloendotheliosis (eosinophilic granuloma, Schuller

Christian disease and Letterer-Siwe disease). Am f Med 1957;22:636-52.

Lancet 1984;: :253-4.

\title{
Bone changes occurring spontaneously and caused by oestrogen in early postmenopausal women: a local or generalised phenomenon?
}

\author{
ANDERS GOTFREDSEN, \\ LISBETH NILAS, \\ CLAUS CHRISTIANSEN \\ BENTE JUEL RIIS, KARSTEN THOMSEN,
}

\section{Abstract}

Regional values of bone mineral content and bone mineral density were calculated from total body dual photon absorptiometry scans of 52 early postmenopausal women treated with oestrogen for one year and of 52 similar women treated with placebo. The six regions were head, arms, chest, spine, pelvis, and legs. In addition, bone mineral density of the lumbar spine was measured by dual photon absorptiometry and bone mineral content of the forearm by single photon absorptiometry, using separate special purpose scanners.

All regions were unchanged after one year of treatment with oestrogen, excluding the lumbar spine, for which values rose. Values for all regions except the lumbar spine fell significantly in the placebo group. The rates of loss ranged from $2 \%$ to $8 \%$, with no significant differences among the regions.

It is concluded that loss of bone in the early menopause is a generalised phenomenon, affecting all parts of the skeleton. Furthermore, oestrogen prophylaxis for loss of bone is effective in all parts of the skeleton. Finally, it is suggested that the measurement of bone mineral content in the forearm should be used for clinical follow up of bone changes, as this method is superior to others in the ratio of change to precision.

\footnotetext{
Department of Clinical Chemistry, Glostrup Hospital, University of Copenhagen, Glostrup, Denmark

ANDERS GOTFREDSEN, MD, registrar

LISBETH NILAS, MD, registrar

BENTE JUEL RIIS, MD, research fellow

KARSTEN THOMSEN, $M D$, registrar

CLAUS CHRISTIANSEN, MD, chief physician

Correspondence to: Dr Gotfredsen.
}

\section{Introduction}

We have developed a method for measuring total body bone mineral in vivo by dual photon absorptiometry. This measurement has $\overrightarrow{0}$ advantages over other estimates of bone mass. Firstly, it directly 3 reflects the mineralisation of the whole skeleton and, secondly, it allows the bone mineral content of particular sites to be calculated. As the total skeleton and the bones in the distal forearm contain thes same ratio of trabecular to cortical bone, the bone mineral content of the forearm is a good indicator of total body bone mineral in bothnormal subjects and patients with disorders of calcium metabolism.

It is not known whether the rate of bone mineral loss is the same in trabecular and cortical bone tissue or whether this loss occurs at the same rate in different parts of the skeleton. 2 The principal question, therefore, is where to measure bone mass for both follow up and diagnosis. It is also not known whether the effect of treatment with oestrogen is uniform throughout the skeleton.

The aim of this study was to compare spontaneous changes in different parts of the skeleton with those caused by oestrogen and to find a measuring site with optimum sensitivity for follow up in early postmenopausal women.

\section{Methods}

Regional bone mineral content was measured by dual photon absorptio metry on a whole body scanner, originally developed in our laboratory to $\overrightarrow{\mathbb{Q}}$ measure total body bone mineral. ${ }^{1}$ The radiation source is $3.7 \times 10^{10} \mathrm{~Bq}$ ( 1 Ci $\frac{}{\mathbb{D}}$ gadolinium- 153 with principal photo peaks at $44 \mathrm{keV}$ and $100 \mathrm{keV}$. During the 90 minutes of scanning the subject lies supine with the source under the scanning table and the detector above. The subject is scanned in a rectilineaf raster pattern with a transverse scan speed of $1 \mathrm{~cm} / \mathrm{s}$ and longitudinal steps oD $2.5 \mathrm{~cm} .{ }^{1}$ Total body bone mineral (and bone mineral content) is calibrated weekly against standard dry defatted bones. Bone mineral density is calculated by dividing by the projected skeletal area. ${ }^{3}$ Calculation of the bone 
mineral density allows for bone and body size as well as correcting for errors of reselecting the particular regions of interest. Regional bone mineral content and density were measured in the head, arms, chest, spine, pelvis, and legs. The accuracy of the measurement of total body bone mineral is $1.5 \%$. ${ }^{4}$ The precision of total body bone mineral is $1.3 \%$, and the precision of regional bone mineral content and density values is between $2 \%$ and $7 \% .^{3}$ The amount of radiation absorbed during one scan is $50 \mu \mathrm{Gy}(5 \mathrm{mrad})$.

Bone mineral density in the lumbar spine was measured on a Lunar Radiation Corporation DP3 spine scanner, using dual photon absorptiometry and a $3.7 \times 10^{10} \mathrm{~Bq}(1 \mathrm{Ci}){ }^{153} \mathrm{Gd}$ source. ${ }^{10} 11$ This scanner operates over the lumbar portion of the spine in a maximum scanning area of $28 \times 20 \mathrm{~cm}$. The transverse speed is $2.5 \mathrm{~mm} / \mathrm{s}$, and the 40 non-overlapping longitudinal steps are $4.5 \mathrm{~mm}$ each. The counting intervals are of $0.5 \mathrm{~s}$, yielding a pixel size of $1.25 \times 4.5 \mathrm{~mm}$. Bone mineral density of the lumbar spine in this report is calculated as the sum of the values obtained from L2, L3, and L4. The long term precision is $3-5 \%$ (unpublished findings) and the accuracy $5-9 \% .^{12}$

Bone mineral content in the distal forearm was measured on a BMA 1100 bone mineral analyser from Nuclear Data Corporation by single photon absorptiometry, using a $3 \cdot 7 \times 10^{\prime} \mathrm{Bq}(100 \mathrm{mCi})$ iodine- 125 source. ${ }^{17} \mathrm{Six}$ scans were performed on each forearm. Measurement of bone mineral content includes both the radius and the ulna and is expressed in arbitrary units (dimension $=$ mass $/$ unit length). The long term precision is $1 \cdot 2 \%$.

\section{Subjects}

This study was part of a large double blind controlled clinical trial, which was undertaken primarily to investigate the efficacy of different treatment regimens in the prophylaxis of postmenopausal osteoporosis. ${ }^{14}$ All of the 270 women in the trial were free of past or present diseases known to influence calcium metabolism or to contraindicate the drugs used in the trial, and of these, 104 women were selected for our study. Fifty two women (17 $\beta$ oestradiol group) received either percutaneous oestrogen (17 $\beta$-oestradiol) treatment (one daily dose of $5 \mathrm{~g}$, corresponding to $3 \mathrm{mg} 17 \beta$-oestradiol) or sequentially administered oestrogen and gestagen (11 tablets containing $2 \mathrm{mg} 17$ p-oestradiol and 10 tablets containing $2 \mathrm{mg} 17$-oestradiol and $1 \mathrm{mg}$ cyproteroneacetate, with an interval of one week), and 52 women (placebo group) received corresponding placebo treatment. The treatment lasted for one year.

All women gave consent after a full explanation of the consequences of participation in the study. Approval of research protocols was obtained from the local and national ethical committees.

All changes in bone mass were calculated as a percentage of the initial value. For the evaluation of significance of changes or differences in single variables Student's $t$ tests for paired or unpaired observations were used. For the evaluation of the overall significance of changes in multiple variables in the same group of subjects the one way analysis of variance was used (as the different variables had been standardised to percentage changes).

\section{Results}

The table gives relevant clinical data, showing that the two groups were well matched for all variables. Figure 1 shows that the bone mineral content in almost all the investigated areas decreased significantly in the group receiving placebo $(p<0.01$ to $p<0.001)$, whereas the bone mass remained unchanged in the group treated with oestrogen. The differences between the two groups were significant in all regions except for the pelvis and the spine.

Patient details of 104 early postmenopausal women. (Values are means (SD)

\begin{tabular}{|c|c|c|c|c|}
\hline & $\begin{array}{c}\text { Age } \\
\text { years: }\end{array}$ & $\begin{array}{l}\text { Menopausal age } \\
\text { (months) }\end{array}$ & $\begin{array}{l}\text { Height } \\
(\mathrm{cm})\end{array}$ & $\begin{array}{l}\text { Weight } \\
\mathrm{kg}\end{array}$ \\
\hline Ethinyloestradiol group & $49 \cdot 8(2 \cdot 7)$ & $15 \cdot 7 \quad 9 \cdot 6$ & $163 \cdot 0+4 \cdot 9$ & $62 \cdot 7 \quad 10 \cdot 4$ \\
\hline Placebo group & $50 \cdot 5(2 \cdot 0)$ & $19 \cdot 8(11 \cdot 2)$ & $162 \cdot 5 \cdot 5 \cdot 2$ & 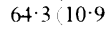 \\
\hline
\end{tabular}

The use of regional bone mineral density instead of content did not alter the picture. There was no significant difference in the percentage changes in the six regions in the placebo group.

Figure 2 shows the values after one year of treatment for the bone mineral density of the lumbar spine (L2-L4), and total spine and the bone mineral content of the forearm in both groups, calculated as a percentage of the initial values. Bone mineral density of the total spine and content of the forearm were unchanged in the group receiving oestrogen, but the bone mineral density of the lumbar spine rose significantly $(3 \cdot 7 \%, p<0.001)$. In the group receiving placebo the bone mineral density of the total spine and content of the forearm both decreased (by $4 \cdot 2 \%, 2 \cdot 8 \%, \mathrm{p}<0 \cdot 001$ ), but the bone mineral density of the lumbar spine remained unchanged. The difference between those treated with placebo and those treated with oestrogen was significant with all three methods. The variability of bone mineral content of the forearm, expressed as the standard deviation of the percentage change, was $1 \cdot 5 \%$, compared with $5 \cdot 8 \%$ and $7 \cdot 1 \%$ for bone mineral density of the total and lumbar spine, respectively. The ratio of change to precision of the bone mineral content of the forearm, therefore, was in the order of two compared with $0 \cdot 5-0 \cdot 7$ for the spinal measurements.
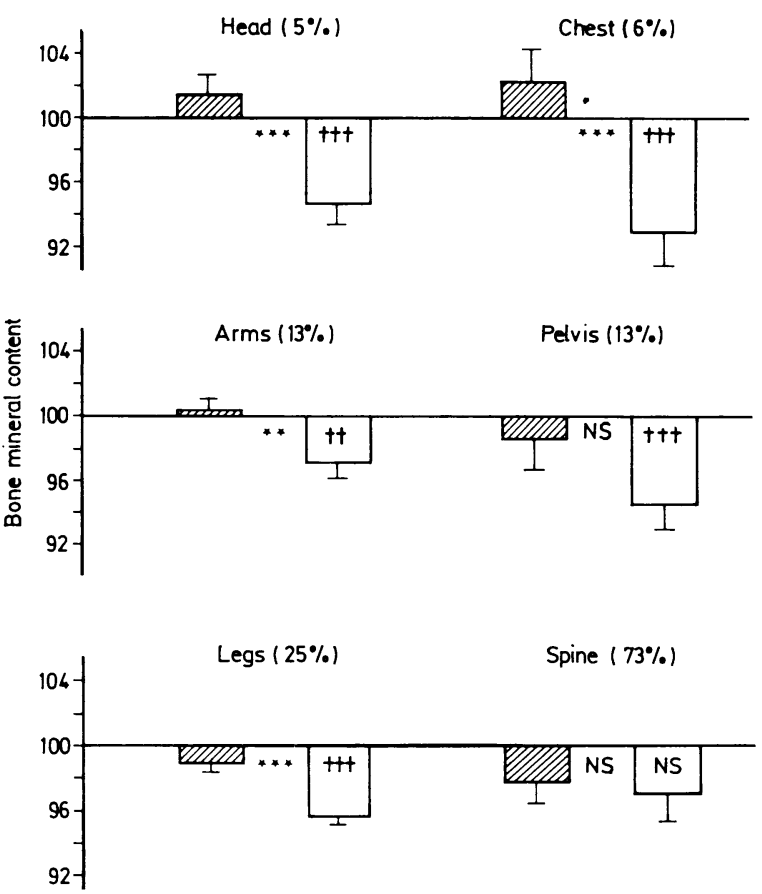

FIG 1-Regional bone mineral content values after one year of treatment with oestrogen $\square$ or placebo $\square$ in early postmenopausal women. Values were calculated as \% of initial levels and are given as mean (SEM). Percentages in brackets indicate the fraction of trabecular bone in the respective regions. ${ }^{19}$

Paired data: $+\dagger \mathrm{p}<0.01$, + t十 $\mathrm{p}<0.001 ;$ unpaired data: ${ }^{\star \star} \mathrm{p}<0.01$, $\star \star \star \mathrm{p}<0 \cdot 001$.

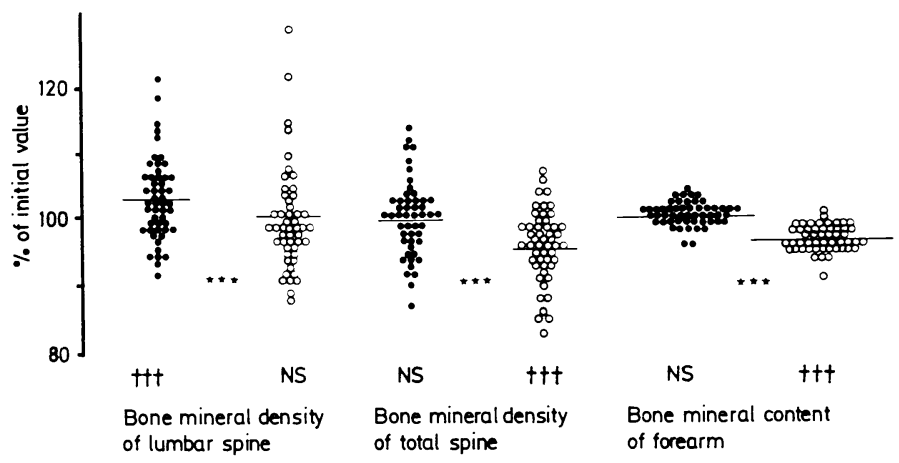

FIG 2-Bone mineral density of lumbar spine and total spine and bone mineral content of forearm after one year of treatment with oestrogen $(0)$ or placebo $(O)$ in early postmenopausal women. Values were calculated as $\%$ of initial levels.

Paired data: $+\dagger+p<0.001$, unpaired data: ${ }^{\star \star \star} p<0.001$.

\section{Discussion}

Women lose bone mineral content after the menopause, ${ }^{7}{ }^{8} 15-18$ and in some this loss is followed by the development of manifest osteoporosis. Osteoporosis is characterised by fractures in the forearm, spine, or neck of femur without adequate trauma. These three sites have different compositions of trabecular and cortical bone. ${ }^{19}$

The data for the placebo group show that the loss of bone in the early menopause is a generalised phenomenon that affects all parts 
of the skeleton. This has not been shown previously. Other workers have found that the rate of loss from trabecular bone tissue is different from that of cortical bone tissue, and thus the rate of loss differs in different parts of the skeleton. ${ }^{2}{ }^{8}$ They recommend that postmenopausal loss of bone should be measured in predominantly trabecular areas. Our results suggest that such a distinction may be unnecessary.

The difference between rates of loss in the six regions was not significant. With reproducibility error of between $2 \%$ and $7 \%$, however, a type two error must be considered. Another year of follow up will probably disclose changes showing a higher rate of loss in the trabecular areas. Comparisons of groups of osteopenic patients with normal subjects and groups of old people with young people have shown different properties in the different parts of the skeleton.

The yearly rate of loss ranges from $2 \%$ (arms) to $8 \%$ (chest). These values are similar to those found in other longitudinal studies of loss of bone during the menopause ${ }^{1 / 1 / 2}$ and cross sectional data. ${ }^{*}$ is 18

Treatment with oestrogen has been shown to prevent postmenopausal loss of bone in the forearm,,$^{1-2021}$ and our data from the group treated with oestrogen show that loss of bone is prevented in all parts of the skeleton. Recent data from our laboratory ${ }^{1-21}$ showed an increase in bone mineral content of the forearm during postmenopausal treatment with oestrogen and progestogen, which was probably due to the norethisterone acetate component. ${ }^{1-21}$ In our study half of the women received unopposed oestrogens and the other half received cyproterone acetate as the gestagen agent.

There was a significant difference between patients receiving oestrogen and those receiving placebo in the bone mineral density of the total spine (fig 2) but not in the bone mineral content (fig 1). For follow up measurements bone mineral content values should be used, because calculation of bone mineral density depends on the estimation of the area of interest and therefore introduces another source of variability. For comparisons between groups bone mineral density values may be more adequate, as division by the area scanned corrects for the individual variability. Furthermore, bone mineral density values may be preferable in longitudinal spinal measurements, as division by the area scanned also corrects for the errors of repositioning or reselecting the edges and borders of the region.

Figure 2 shows that for clinical use-that is, in the single patient-measurement of bone mineral content of the forearm is superior to that of spinal bone mineral density for estimation of bone changes, because the ratio of change to precision is higher for bone mineral content.
This study was supported by grants from The Danish Medical Researclo Council (number 12-4716), Gangstedfonden, Fabrikant Einar Willumsens Mindelegat, and The Dagmar Marshall Fund. We thank the Scherin company for supplying the oral oestrogen and gestagen and Laboratorie? Besins-Iscovesco for the percutaneous oestrogen. We also thank the 10 促 women who took part in the study.

\section{References}

1 Gotfredsen A, Borg J, Christiansen C, Mazess RB. Total body bone mineral in vivo by dual phot absorptiometry. I. Measurement procedures. Clin Phvsiol 1984;4:343-55

2 Mazess RB, Peppler WW, Chesney RW, Lange TA, Lindgren U, Smith E Jr. Total body an regional bone mineral by dual photon absorptiometry in metabolic bone disease. Calcif Tissu Int 1984;36:8-13.

3 Gotfredsen A, Borg J, Nilas L, Tjellesen L, Christiansen C. Representativity of regional to tot bone mineral in healthy subjects and "anticonvulsive treated" epileptic patients. Measuremen by single and dual photon absorptiometry. Eur 7 Clin Invest in press.

by single and dual photon absorptiometry. Eur $\mathcal{f}$ Clin Invest (in press). Als OS, Gotfredsen A, Christiansen C. Relationship between local and total bone mineral Tjellesen L, Gotfredsen A, Borg J, Christiansen C. Relationship between local and total bodv bone minera.

6 Nilas L, Gotfredsen A. Christiansen C. The relationship between local and total bone minerat content after gastric surgery. Scand f Gastroenterol 1984:19:591-5.

Riggs BL, Wahner HW, Dunn WL, Mazess RB. Offord KP, Melton IJ. III. Differential chang in bone mineral density of the appendicular and axial keleton with aging. Relationship to spin usteoporosis. f Clin Invest 1981;67:328-35.

8 Riggs BL, Wahner HW', Seeman E, et al. Changes in bone mineral densits of the proximal femuT. and spine with aging. Difference between the postmenopausal and senile osteoporos
syndromes. 7 Clin Invest 1982;70:716-23 syndromes. $f$ Clin Invest 1982;70:716-23.

absorptiometry J, Christiansen C, Mazess RB. Total bo

10 Lunar Radiation Corporation. Operating manual for the Lunar Radiation DP3 spine scann Madison: Lunar Radiation Corporation, 1984.

11 Dunn WL, Wahner HW, Riggs BL. Measurement of bone mineral content in human vertebr and hip by dual photon absorptiometry. Radiolog. 1980;136:485-7.

12 Wahner HW, Dunn WL, Mazess RB, et al. Dual photon ${ }^{153}$ Gd absorptiometry of bone. Radiolog 1985:156:203-6.

13 Christiansen C, Rodbro P, Jensen $\mathrm{H}$. Bone mineral content in the forearm measured by photon absorptiometry. Scand f Clin Lab Invest 1975;35:323-30

14 Christiansen C, Riis BJ, Nilas L, Rodbro P, Deftos L. Uncoupling of bone formation bon resorption by combined oestrogen progestogen therapy in postmenopausal osteoporosis. Lan $1985 ; \mathrm{i}: 800-1$

15 Smith DM, Khairi MRA, Johnston CC Jr. The loss of bone mineral with aging and its relationship. to risk of fracture. $\mathcal{F}$ Clin Incest 1975;56:311-8

16 Johnston CC Jr, Norton JA, Khairi RA, Longcope C. Age related bone loss. In: Barzel U, e Osteoporosis II. New York: Grune and Stratton, 1979:91-100.

17 Christiansen C, Christensen MS, McNair P, Hagen C, Stocklund KE, Transbol I. Prevention

early postmenopausal bone loss. Eur f C Clin Inzest 1980;2:273-9.
18 Krsiner B, Pors Nielsen J. Bone mineral content of the lumbar spine in normal and osteoporot women: cross-sectional and longitudinal studies. Clin S Si 1982;62:329-36.

19 Johnson LC. Morphologic analysis in pathology. The kinetics of disease and general biology bone. In: Frost HM, ed. Bone biodynamics. Boston, Massachusetts: Little, Brown an $\mathscr{Q}$

20 Lindsay R, Aitken JM, Anderson JB, Hart DM, MacDonald EB, Clarke AC Long-tern prevention of postmenopausal osteoporosis by oestrogen. Lancet 1976;1:1038-41.

21 Christiansen $\mathrm{C}$, Christensen MS, Transbol $\mathrm{I}$. Bone mass in postmenopausal women aft $\underset{D}{\bar{D}}$ withdrawal of oestrogen gestagen replacement therapy. Lancet 1981;i:459-61.

Accepted 3 March 1986

\section{YEARS AGO}

The truest recreation for mind or body is to be found in change of work. The thesis might be illustrated by the habits of many, nay, most of those who have left an enduring name; but we need not go beyond the events of the last few months in search of an example; we have seen Mr. Gladstone and Professor Huxley turn aside from their engrossing labours, to engage in a lively discussion of a point in transcendental philosophy. Many members of the medical profession have, especially in past time, earned considerable reputation in other fields of work which have afforded relaxation for spare hours. Dr. Oliver Wendell Holmes has written with his usual clear insight and happy choice of illustrations on this matter, and Dr. Quain did well to advise the medical officers leaving Netley to think upon it. Science already owes many debts to medical officers of the public services serving abroad. Within the strict limits of medicine and pathology, much yet remains to be learnt, which they are well able to teach us. Leaving aside the subject of infectious diseases, and the relation in which micro-organisms stand to those diseases, a harvest which now seems ripe for the sickle, leisure hours may be usefully given to the study of meteorology, especially of climate, in relation to disease; to the distribution of disease, and its relation, on the one hand, to meteorological, geological, or geographical conditions, and, on the other, to the social peculiarities of nations and tribes. For the study of folk-lore, which is casting much fresh light on the habits and thoughts of primeval man, members of our profession possess peculiar advantages; they are mos fortunately placed to learn customs and superstitions which have gathere round the death-bed, or the cradle of the newly born child. It is a shallow. pate which will merely laugh at these things; they may appear absurd enougn్ in the nineteenth century, but they all have some meaning, had we but the wit to understand it. Even in the England of to-day, traces remain; the lighted taper left with a corpse at night is the distinct survival of a very ol and widely honoured superstition; and our wedding customs - the wedding breakfast and the subsequent honeymoon, point clearly to the ancienब marriage by capture. Apart from the general interest attaching to such ${ }^{+}$ subjects, the folk-lore regarding plants may afford valuable therapeutic suggestions, resulting in the introduction of such useful remedies as, if we्? may believe the story, salicin and its allies. Medicine is an engrossing profession; the strictly cognate sciences cover a wide field; and even withio such boundaries, recreation in change of work may be found. the medicaf officers who leave Netley have received at least an elementary training in biology, and they are therefore in a position to choose a line of work in one of other department of the biological sciences which will, if systematicalle pursued, conduct to results of value directly or indirectly to themselves anf the profession to which they belong.

(British Medical fournal 1886;i:511.) 